\title{
NALAR FIDYAH \\ (TELAAH MAQASID AL-SYARIAH AL-IQTISHADIYAH)
}

\author{
Jefry Tarantang ${ }^{1}$, Ahmad Dakhoir ${ }^{2,}$ Balya Nasim Ahmad $^{3}$ \\ IAIN Palangka Raya ${ }^{123}$ \\ jefry.tarantang@iain-palangkaraya.ac.id
}

\begin{abstract}
This research is a study of sharia reasoning regarding fidyah or relief from not carrying out Ramadan fasting in the study of maqashid al-syariah al-iqtishadiyah, by knowing the objectives, secrets and virtues, as well as their context in the development and economic development of the people. This research is library research with a multi-approach study of the concept of fidyah according to Islam, then looks at the implementation of fasting fidyah through maqashid al-sharia and in an economic context. This research uses a conceptual, historical, and contextual approach. The results of this study Allah wants ease of worship, especially in fasting by not forcing servants to fast for the elderly, such as the elderly or the elderly, pregnant and nursing mothers, people who experience illness with very little hope of recovery, and people who work hard. The obligation of fidyah be paid by feeding the poor and needy in a dose of one mudd or equal to 15 tahil or 567 grams or it can also be converted into staple food. Fidyah payments can be made at any time, if it is delayed then the payment will be doubled. According to the maqashid sharia, fidyah is a form of benefit and goodness given by God to his servants with regard to three elements of care, namely religion, soul and wealth. The release of wealth to elderly Muslims, fidyah also gave birth to an indication as an instrument and potential as well as economic development for the people, especially the poor. the implementation of fidyah has value, wisdom, and benefit to the giver and recipient of fidyah.
\end{abstract}

Keywords: fidyah, maqashid al-syariah, al-iqtishadiyah.

Sebuah keniscayaan dan suatu kewajiban bahwa puasa ramadhan adalah perintah Allah kepada Umat Islam bagi siapa saja yang diwajibkan atasnya berpuasa atau mampu selayaknya yang telah diatur oleh nash maupun syarak (Kemendikbud RI, 2016: 1630). Dalil kewajiban berpuasa juga terdapat pada surah al-Baqarah ayat 183 (Kemenag RI, 2013: 26). Sebagaimana pada firman Allah mengenai keringanan bagi seseorang yang tidak mampu menjalankan ibadah puasa dengan memberikan alternatif lain sebagai gantinya tidak mampu menjakankan ibadah puasa dengan membayar fidyah yang artinya tebusan (Mahmud Yunus, 1990: 130) kepada fakir miskin yang tertulis pada ayat 184 surah al-Baqarah (Departemen Agama, 2006: 35).

Selain itu bahwa, diamati dan dilihat pada hadits, pendapat ulama serta literatur lain, keringanan atau alternatif lain bagi seorang yang tidak bisa berpuasa termasuk antara lain adalah orang sakit parah, manula, musafir atau dalam sedang menjalankan perjalanan, haid, wanita hamil dan menyusui serta nifas (Sayyid 
Sabiq, 2013: 217). Adapun orang yang bekerja berat di siang hari yang pada itu sangat memberatkan untuk dilakukannya menjalankan ibadah puasa, masih dalam perdebatan dan perbedaan pandangan disebagian kalangan ulama mazhab. Semua itu bisa diganti dengan mengganti puasa di hari pada bulan lain atau membayar fidyah. Pokok permasalahan dan bahasan yang diangkat adalah pada ayat 184 alBaqarah, yaitu Allah memberikan keringanan bagi hambanya yang tidak mampu dan berat untuk melaksanakan puasa ramadhan tetapi Allah memberikan keringanan dengan membayar fidyah kepada fakir miskin.

Perintah Allah atau Ibadah yang dilaksanakan pada umat Islam tentunya tidak terlepas dari pemahaman yang benar dan juga keliru disisi masyarakat umat Islam. Usaha pemahaman kepada masyarakat ialah siapa sajakah yang boleh berbuka dan tidak melaksanakan puasa lalu ia membayar fidyah sebagai tebusan pengganti ibadah puasa yang tidak mampu dilakukannya, karena dalam mengarungi kehidupan dan menjalankan ibadah pada tatanan umat Islam, pasti ditemui fenomena kekeliruan pemahaman dikalangan umat Islam, yaitu seorang dengan sengaja berbuka saat puasa tanpa ada uzur (Kemendikbud RI, 2016: 1837) lalu dilanda kemalasan untuk menjalankannya dan menganggap mengganti puasanya cukup membayar dengan fidyah.

Aspek lain yang ingin digali pada fidyah sebagaimana yang sesuai diinginkan dengan al-Quran adalah bentuk pembayarannya. Karena ada perbedaan pemahaman dikalangan ulama mazhab mengenai pembayaran, terlebih lagi terhadap masyarakat. Jika diamati bersama secara komprehensif pada literatur nash, hadits dan kaidah bahasa Arab bahwa pada ayat 184 surah al-Baqarah, kata “طعم" (Tho'am) itu bermakna makanan (Muhammad Ar Razi, 1989: 435) atau yang sudah siap saji, sedangkan dalam beberapa tafsiran mufassir, hadits dan pendapat lain bahwa bisa saja memberikan bahan makanan pokok kepada fakir miskin, misalnya satu mudd kurma, beras, atau gandum dan bahan makanan pokok lainnya yang sesuai dengan tradisi daerah setempat (Nasa'i, 1991: 175).

Kemudian aspek yang lainnya adalah sasaran atau sang penerima fidyah. Dalam ayat 184 surat al-Baqarah disebutkan bahwa pembayaran fidyah harus 
ditujukan kepada orang miskin. Karena mungkin saja asumsi bahwa dikalangan orang yang keliru memahami ayat 184 surah al-Baqarah cukup membayar atau mentraktir makan teman atau saudaranya yang mungkin saja ia masih mampu atau tidak termasuk golongan orang miskin. Berangkat dari aspek dan masalah diatas, yang dianggap cukup signifikan untuk dikaji bahwa kiranya fidyah perlu diupayakan penelitian sebagaimana yang sesuai dengan pemahaman al-Quran melalui para mufassir dan pendapat ulama mazhab, agar fidyah bisa diamalkan sesuai al-Quran dan masyarakat atau umat Islam dalam pelaksanaan ibadah mendapatkan nilai taqwa sebagaimana juga menjalankan ibadah puasa yang tidak mampu ia lakukan. Jika fidyah tidak diamalkan sesuai al-Quran maka maksud syariat ibadah puasa dan penggantian puasa sebagai alternatif yaitu fidyah,maka maksud disyaratkan fidyah kemungkinan tidak terpenuhi dan golongan taqwa pun tidak didapatkan apa lagi ridho-Nya.

Fidyah yang disyariatkan bagi yang sulit untuk berpuasa terhadap kekhawatiran jiwa dan kesehatan seseorang seperti manula, orang yang sakit, dan ibu hamil atau sedang menyusui merupakan keringanan dari sifat kemurahan Allah SWT terhadap hambanya. Selanjutnya upaya pengkajian syariat fidyah dan pendalaman fidyah melalui pendekatan kontekstualitas ekonomi syariah dengan memandang melalui teori maqasid al-syariah al-Iqtishadiyah terlebih jika dilihat dari data kementrian kesehatan lansia berjumlah 15. 401.717 (usia non produktif) jiwa dan jumlah ibu hamil 5.291.143 jiwa (Kementerian Kesehatan RI, 2019: 6), dilihat dari data tersebut apabila fidyah dikonversi menjadi uang senilai Rp50.000 atau Rp30.000 akan memberikan dampak dan potensi terhadap pengembangan terhadap ekonomi jika dipandang melalui iqtishadiyah atau ekonomi, terlebih penduduk umat Islam di Indonesia telah diakui cukup mayoritas dan berjumlah sangat besar. Daripada itu maka jika di alokasikan, dihimpun, dan diberdayakan kiranya dana fidyah akan memberikan dampak ekonomi yang produktif terhadap kesejahteraan fakir miskin. Melalui itu semua, usaha penelaahan maksud, rahasia dan hikmah dari Allah SWT menurunkan perintah membayar fidyah ketika 
seseorang mendapatkan uzur sehinggalah tidak bisa menjalankan ibadah puasa akan dapat ditemui.

\section{METODE}

Penelitian ini menggunakan kajian pustaka (Prayetno Irawan, 1999: 65) atau literature review (Arikunto, 2002: 75). Penelitian ini juga merupakan penelitan normatif (Tarantang, 2018: 29) yang dianalisis secara kualitatif deskriptif dengan pendekatan maqasid syariah, konseptual, historis, dan kontekstual.

\section{Pemaknaan Maqasid Syariah, Al-Iqtishad, Puasa dan Fidyah}

Menurut Imam al-Ghazali, tujuan utama syariah adalah mendorong kesejahteraan manusia, yang terletak dalam perlindungan terhadap agama mereka (li hifdzil al-din), diri (li al-nafs), akal (li hifdz al- 'aql), keturunan (li hifdzil alnasl), harta benda (li hifdzil al-mal). Apa saja yang menjamin terlindungnya lima perkara ini berarti melindungi kepentingan umum dan dikehendaki. Implikasi lima perkara ini dalam ilmu ekonomi perlu disadari bahwa tujuan suatu masyarakat muslim adalah untuk berjuang mencapai cita-cita ideal. Perlunya mendorong pengayaan perkara-perkara ini secara terus-menerus sehingga keadaan makin mendekat kepada kondisi ideal dan membantu umat manusia meningkatkan kesejahteraannya secara kontinyu.

Kata al-iqtishad yang kemudian diterjemahkan ke dalam bahasa Indonesia menjadi ekonomi, terambil dari kata qasd. Kata ini dengan segala derivasinya disebut sebanyak enam kali di dalam al-Qur'an. Al-Isfahani menuliskan bahwa makna kata al-iqtishad yang akar katanya adalah al-qasd, bermakna istiqamah altariq (jalan lurus). Jika disebut kata qasadu qasdahu maknanya nahawtu nahwahu. Selanjutnya al-Iqtisad memiliki dua sisi, salah satunya adalah yang mahmud (terpuji) seperti al-jud (kesederhanaan) merupakan sifat yang baik antara al-israf (boros) dan al-bukhl (Pelit). Demikian juga dengan syaja'ah (berani) adalah sifat yang baik antara al-tahawwur (nekat) dan al-jubn (pengecut). Sedangkan sisi lainnya adalah taraddud (plin-plan atau ragu) antara yang mahmud 
dengan yang mazmum. Contohnya adalah al-waqi' antara adil dan melampaui batas. Yang dekat dengan yang jauh (Al-Isfahani, 2004: 451-452).

Menurut bahasa Arab, ekonomi dinamakan al-mu'amalah al-madiyah, yaitu aturan-aturan tentang pergaulan dan perhubungan, manusia mengenai kebutuhan hidupnya. Disebut juga al-iqtishad, yaitu pengaturan soal-soal penghidupan manusia dengan sehemat-hematnya dan secermat-cermatnya (Idri, 2015: 2). Secara istilah, pengertian ekonomi Islam dikemukakan dengan redaksi yang beragam di kalangan para pakar ekonomi Islam. Menurut Mohammad Nejatullah Siddiqi, ekonomi Islam adalah jawaban dari pemikir Muslim terhadap tantangan-tantangan ekonomi pada zamannya. Dalam upaya ini mereka dibantu oleh al-Quran dan sunnah Nabi, akal pikiran, dan pengalaman (Siddiqi, 2010: 146).

Puasa adalah sebutan yang telah umum, berasal dari bahasa Sanskerta upawasa. Orang jawa biasa menyebut pasa. Sejumlah suku (masyarakat) di Indonesia biasa menyebuat puasa juga. Dalam kitab-kitab Hindu/Buddha kita jumpai sebutan vassa (dari bahasa Pali), yang maksudnya adalah puasa (sismono, 2010: 1). Puasa juga disebut shaum/shiyam (dalam bahasa Arab), asal katanya dari shama-yashumu-shaiman yang artinya menahan diri dari sesuatu, berhenti, diam, atau berada di suatu tempat. Seperti kata-kata shama asrih, artinya angin berhenti berhembus; shamat asy-syams, artinya matahari berada di tengah-tengah langit; shama al-fars, artinya kuda enggan melakukan perjalanan (Sholehuddin, 2004: 1).

\section{Sebab Hukum Kewajiban Fidyah}

Tidak mampu berpuasa

Orang yang mendapat keringanan untuk berbuka adalah orang tua, perempuan yang lemah, orang sakit yang sulit diharap kesembuhannya, dan para pekerja berat yang tidak mendapat penghasilan selain dari pekerjaan tersebut. Mereka semua diperbolehkan berbuka jika puasa amat memberatkan mereka. Namun, sebagai gantinya mereka wajib memberi makan untuk setiap hari satu orang miskin. Kadarnya adalah satu sha' atau setengah sha atau satu mud sesuai 
dengan perselisihan para ulama. Tidak ada keterangan dari As-Sunnah tentang kadar makanan tersebut (Sayyid Sabiq, 2013: 217).

Sakit yang tidak bisa disembuhkan

Orang sakit yang tidak dapat sehat kembali (Sayyid Sabiq, 2013: 284).

Perempuan hamil dan menyusui

Hukum asal bagi kedua keduanya adalah wajib shaum, yaitu ketika shaum tidak membahayakan dirinya ataupun bayinya maka tetap ia pada hukum asal, yaitu wajib shaum. Untuk itu diklasifikasikan perempuan hamil dan menyusui dalam tiga kelompok. pertama, yang kuat dan baik-baik saja melakukan shaum bagi dirinya dan bayinya. Maka tetap berlaku hukum asal, yaitu wajib shaum. Kedua, yang dapat shaum tetapi dikhawatirkan timbul akibat yang kurang baik terhadap dirinya atau bayinya maka dianjurkan berbuka dan berbuka lebih baik maka ia wajib berfidyah. Ketiga, yang terancam kesehatan atau keselamatan dirinya atau bayinya apabila melakukan shaum. Maka dalam keadaan seperti ini ia wajib tidak shaum atau berbuka shaum, dan ia wajib berfidyah. Hukum yang kedua dan ketiga sejalan dengan fatwa Ibnu Abbas yaitu "Kamu sekedudukan dengan orang yang payah untuk shaum, maka wajib atas kamu fidyah dan tidak ada qadha". Maka baik bershaum atau berfidyah haruslah melalui perhitungan yang hati-hati dan cermat, tidak asal-asalan, dan bukan dengan maksud menghindari kewajiban (Sholehuddin, 2004: 67-68).

Perempuan Nifas dan Menyusui

Apabila melihat nifasnya, maka tentulah ia termasuk yang wajib mengqadha shaum. Tetapi ketika memperhatikan menyusuinya tentulah ia boleh berbuka dan membayar fidyah (Sholehuddin, 2004: 67-68).

Pembayaran dan ukuran fidyah

Cara membayar fidyah yaitu memberi makan fakir dan miskin dengan takaran satu mudd (cupak) beras (675gram) atau makanan pokok. Ukuran satu mudd sebagai ganti satu hari puasa yang tidak ditunaikan. Ukuran satu mudd sama dengan 15 tahil atau 567 gram (566.85 gram) (Al-Zuhayly, 2005: 288).

Penerima/Mustahiq fidyah 
Penerima/mustahiq fidyah adalah fakir dan miskin yang didasarkan pada firman Allah SWT yang berbunyi: Artinya: Orang-orang yang bisa berpuasa tetapi dengan susah payah, (jika tidak berpuasa), (mereka) wajib membayar fidyah, (yaitu) memberi makan seorang miskin. (Al-Baqarah [2]: 184) (Hasan, 2010: 45).

Waktu Membayar Fidyah

Fidyah dibayar sebelum datang bulan puasa (Hasan, 2010: 37). selain itu, seseorang yang diperbolehkan membayar fidyah dari puasa yang ditinggalkannya dapat membayar fidyah tersebut pada hari itu juga ketika dia tidak melaksanakan puasa, atau diakhirkan sampai hari terakhir bulan Ramadhan, sebagaimana dilakukan oleh sahabat Anas bin Malik ketikabeliau telah tua. Yang tidak boleh dilaksanakan adalah pembayaran fidyah yang dilakukan sebelum Ramadhan. Misalnya: Ada orang yang sakit yang tidak dapat diharapkan lagi kesembuhannya, kemudian ketika bulan Sya'ban telah datang, dia sudah lebih dahulu membayar fidyah. Maka yang seperti ini tidak diperbolehkan. Ia harus menunggu sampai bulan Ramadhan benar-benar telah masuk, barulah ia boleh membayarkan fidyah ketika hari itu juga atau bisa ditumpuk di akhir Ramadhan (Hasan, 2010: 38).

Potensi Fidyah Sebagai Instrumen Pengembangan Ekonomi Umat

Pelaksanaan fidyah yang merupakan rukhsah terhadap seorang muslim yang tidak mampu berpuasa melalui harta berupa pemberian tebusan bahan makanan pokok, makanan siap saji, dan atau uang tunai (humas.pasekab.go.id) kepada fakir miskin berimplikasi pada potensi pengembangan ekonomi umat. Pasalnya seseorang yang terkena uzur tidak bisa berpuasa harus menyediakan harta agar dikeluarkan kepada fakir miskin. Melalui tafsir dan komparasi beberapa ulama madzhab terhadap tafsiran seseorang yang diperbolehkan untuk tidak berpuasa dan membayar fidyah seperti lansia dan ibu hamil, melahirkan perkiraan dan anggapan bahwa fidyah berpotensi terhadap pengembangan ekonomi umat, jika dilihat melalui data lansia dan ibu hamil di Indonesia. Menurut sumber data informasi, kemenkes RI 2018 hasil estimasi Jumlah lansia 15. 401.717 (usia non produktif) jiwa dan jumlah ibu hamil 5.291.143 jiwa (Kementerian Kesehatan RI, 2019: 6). Walau tidak semuanya beragama Islam tetapi telah diakui Indonesia 
memiliki umat Islam berjumlah 229 juta jiwa yaitu 87, $2 \%$ dari penduduk Indonesia, yang berjumlah 263 juta jiwa (ibtimes.id). Tentunya juga tidak dapat diperkirakan berapa jumlah lansia beragama Islam dan berapa jumlah ibu hamil, tetapi dengan jumlah umat Islam yang disebutkan tadi, angka tersebut bila dikalkulasikan dengan rupiah menghasilkan jumlah yang cukup besar dan memberikan indikasi serta dapat dijadikan instrument pengembangan ekonomi umat dan masyarakat terkhusus fakir miskin.

Pengembangan ekonomi ini dilihat dari apabila fidyah dikonversi berupa uang tanpa mengesampingkan tebusan berupa bahan makanan pokok atau makanan siap saji. Konversi dilakukan dengan angka rupiah yang telah diungkapkan oleh pejabat publik dari Lembaga Amil Zakat Nasional melalui pernyataannya dengan mengatakan pembayaran fidyah senilai Rp50.000, (detik.com). Maka apabila dikalkulasikan, misal diambil contoh dengan angka 10.000.000 (sepuluh juta) lansia dikalikan Rp50.000 maka akan menghasilkan nilai 500.000.000.000 (lima ratus milyar) hanya untuk lansia saja angka tersebut sungguh sangat banyak belum lagi dikalkulasikan dengan jumlah ibu hamil.

Tentunya disadari, tidak semua manula yang tidak sanggup berpuasa dan tidak semua ibu hamil tidak berpuasa. Tetapi diakui bahwa orang tua rentan dengan lemahnya fisik dan kesehatan pun juga ibu hamil. Melalui pengamatan uraian di atas itulah, fidyah berpotensi terhadap instrument pengembangan ekonomi umat, dengan pemahaman syarat pembayaran berdasarkan nash, kemudian diberdayakan dengan beberapa upaya pengelolaan instrumen lembaga Negara keagamaan yang baik.

Tujuan Fidyah dalam Perspektif Maqashid Syariah Al-Iqtishadiyah

Telah menjadi kepastian dan keniscayaan segala syariat yang Allah turunkan memiliki implikasi dan maksud terhadap hambanya, juga pelaksanaan fidyah kepada fakir miskin yang menjadikan seorang muslim yang tidak bisa menjalankan ibadah puasa lantaran uzur syar'i. Dilihat dari kajian keilmuan usul figh maka illah atau motif timbulnya hukum (Abdul Helim, 2019: 12) dari dibolehkannya seorang tidak berpuasa adalah kepada kondisi kesehatan atau 
pemeliharaan jiwa terhadap hambanya. Allah mempunyai keinganan (iradah) dan kemudahan kepada hambanya untuk tidak menyulitkan melaksanakan syariat yang diberikan kepada hambanya. Sebagaimana dari itulah syariat keinganan Allah memberikan keringanan alternatif kepada hambanya yang tidak mampu menjalankan ibadah puasa Ramadan seperti yang telah ditentukan dalam nash bahwa Allah sang pemilik syariat menerapkan prinsip maslahah dalam syariat Islam, dan dengan keringanan itu memberikan manfaat lebih dan tidak mengurangi nilai ibadah puasa, serta Allah menginginkan pencegahaan kemudharatan dari kesusahan melaksanakan ibadah sebagaimana syariat menghendaki kebahagiaan dunia dan akhirat bagi hambanya.

Menghilangnya kesusahan bagi yang terbebani uzur sehunggalah tidak bisa berpuasa, dan menghadirkan kemudahan dalam beribadah Keringanan ini selaras dengan kaidah fiqh yaitu "kesulitan mendatangkan kemudahan". Melalui konteks maqasid syariah dapat juga diamati bahwa maksud rukhsah keringanan ini memberikan pemahaman bahwa Allah sang pencipta dan pemberi syariat kepada hambanya menggambarkan sifat Rahman (pengasih) dan Rahim (penyayang) agar hambanya tidak mengalami kesulitan dalam menjalani ibadah puasa.

Seorang muslim tidak mampu menjalankan ibadah puasa, tidak mengurangi nilai pahala dan ridho Allah SWT. Melalui pandangan maqasid syariah pada usul khamsah atau lima unsur pokok maqasid syariah dalam pemeliharaan, berimplikasi maslahah kebaikan atau manfaat ketika seorang muslim terkena uzur. Menurut maqasid syariah, fidyah dengan melihat keringanan dan alternatif tidak memaksakan untuk berpuasa bagi yang uzur atau dilihat dari illah terhadap keselamatan jiwa terhadap manula, ibu hamil, dan sakit parah, maka fidyah bisa diasumsikan melalui maqasid syariah terhadap unsur pemeliharaan jiwa (hifzun-nafs) pun terpenuhi. Kemudian pada pengamatan pelaksanaan fidyah dengan memberi makan seorang fakir miskin juga masuk dalam penjagaan unsur maqasid syariah yaitu penjagaan terhadap harta (hifz almal), bahkan ketika seorang uzur tidak bisa berpuasa dengan memberikan kepada 
fakir miskin sebuah makanan melalui harta yang dia miliki, maka ia juga menyelamatkan jiwa (hifzun-nafs) dan harta (hifz al-mal) kepada fakir miskin atau si mustahik. Fidyah merupakan syariat Allah terhadap orang yang tidak mampu berpuasa dengan syarat dan uzur yang telah ditetapkan al-Quran, maka dalam pelaksaannya sudah barang tentu merupakan Ibadah mahdah kepada Allah yaitu fidyah juga merupakan unsur pemeliharaan agama (hifz al-Din).

Agar lebih mudah memahami fidyah dalam bingkai perspektif maqasid syariah penulis membuat tabel terhadap unsur maqasid syariah, jika fidyah dilaksakan sesuai al-Quran, agar kiranya maksud syariat bisa dilihat secara jelas dan prinsip maslahah disetiap syariat bisa ditemui. Pelaksanaan fidyah dari lima unsur pemeliharaan, ada tiga unsur pemeliharaan yang dicapai dan dipenuhi, yaitu pemeliharaan agama, jiwa dan harta. Syariat fidyah yang dibebankan terhadap muslim yang tidak mampu berpusa karena uzur, ternyata jika diamati melalui maqasid syariah pada unsur pemeliharaan melahirkan atau memiliki implikasi terhadap maslahah dan kebaikan terhadap hamba-hambanya dengan Allah memberikan jalan alternatif mengganti puasa dengan tebusan berupa membayarr, memberikan kepada fakir miskin berupa makanan atau bahan makanan pokok. Sifat kasih sayang Allah pun nampak sangat terlihat, melalui syariat ibadah puasa dan keringanan dengan membayar fidyah bagi yang uzur, Allah sangat memperhatikan hambanya yang mengalami kesusahan melalui syariatnya dengan menggiring seorang yang uzur membayar fidyah kepada fakir miskin. Dengan dari pada itulah seorang miskin mendapatkan bantuan berupa makanan yang diberikan oleh seorang uzur berpuasa melalui hartanya. Selain itu, karena makanan merupakan bahan daruriat yang harus ada terhadap kelangsungan hidup maka secara otomatis seorang muslim yang memberikan fidyah kepada fakir miskin telah membantu kelangsungan hidup atau pemeliharaan jiwa. Melalui itu semua maka ibadah puasa yang tidak bisa dikerjakan tetap mendapatkan pahala dari Allah atau jalannya agama dan ibadah tetap tercapai dalam pelaksanaan syariat dari Allah SWT. 
Syariat fidyah yang berawal dari ibadah puasa hingga seorang muslim dibebankan uzur yang termaktub pada nash, lalu memberikan kepada fakir miskin bahan makanan pokok atau uang melalui hartanya, memunculkan nilai ekonomi terhadap kesejahteraan fakir miskin. Demikian hal ini Allah SWT menginginkan harta diantara muslim beredar kepada sesama muslim yang membutuhkan lewat ibadah puasa bagi yang uzur hingga seseorang bisa di alihkan dengan membayar fidyah. Jika dikaitkan hal ini pada pernyataan Allah SWT pada Q.S. al-Hasyr ayat 7 yang bermakna “...agar harta itu jangan beredar di antara orang-orang kaya saja diantara kamu..." (Kementerian Agama, 2013: 545). Pemberian bahan makanan pokok atau berupa uang kepada fakir miskin merupakan konteks iqtishadiyah atau bentuk bantuan ksejahteraan kepada sesama manusia. Penerapan fidyah jika dipandang dapat memberikan kesejahteraan untuk umat melalui suatu pengelolaan dan distribusi yang baik yang sesuai dengan maqasid aliqtihsadiyah.

Pengamatan fidyah pada konteks iqtishadiyah atau pengembangan ekonomi sangan dimungkinkan, pertama dengan data lansia berjumlah 15 . 401.717 jiwa dan data ibu hamil 5.291.143 jiwa jika dikalkulasikan dengan rupiah dengan jumlah pembayaran fidyah Rp50.000 dan atau Rp30.000 memberikan nilai yang cukup banyak, juga jika pembayaran melalui bahan makanan pokok akan memberikan nilai bahan makan yang cukup banyak. Konteks iqtishadiyah memandang adanya secercah harapan pada pelaksanaan fidyah berbasis system terhadap pengembangan ekonomi dengan dan pengelolaan yang baik.

Puasa merupakan ibadah tahunan yang selalu dilaksanakan oleh setiap muslim yang sehat, juga terhadap muslim yang uzur sehingga harus membayar fidyah. Maka perlu diperdayakan, misalnya adanya panitia tahunan khusus fidyah yang mengelola pembayaran, menghimpun dan mengalokasikan dana dan atau bahan makanan pokok. Kemudian fidyah bisa serta merta di berdayakan dengan pengalokasian usaha atau dagangan, hingga hasil tersbut dapat diberikan kepada fakir miskin dan bisa menumbuhkan kesejahteraan fakir miskin. 
Demikianlah segala perintah dan syariat yang Allah turun memiliki nilai dan maksud serta hikmah, bahwa segala syariat yang diturunkan Allah SWT Mempunyai masalahah kebaikan terhadap hambanya, tidak ada sedikit pun dalam syariatnya, Allah menggendaki ksesusahan terhadap hambanya, maka dengan memandang dengan fidyah melalui maqasid syariah sudah barang tentu Allah mengnginkan kemasalahatan bagi hambanya kepada seorang yang uzur tidak bisa berpuasa maupun kepada penerima fidyah, dengan memandang dengan maqasid syariah, fidyah dapat mudah dipahami maksud atau tujuan Allah mensyariatkan fidyah.

Filosofi Fidyah dan Fenomena Lansia dan Ibu Hamil

Melalui disyariatkannya fidyah terhadap seseorang yang tidak mampu berpuasa karena uzur yang telah ditentukan nash, maka dalam maksud syariat Allah menghendaki kemudahan terhadap hambanya yang tidak mampu berpuasa. Maka sudah menjadi kewajiban perintah Allah harus dipenuhi bagi yang mempunyai fisik yang sehat dan keringanan bagi yang tidak mampu berpuasa dengan alternatif pembayaran fidyah kepada fakir miskin. Tujuan dari pensyariatan fidyah lainnya adalah adanya perhatian Allah terhadap hambanya yang kurang memiliki harta atau fakir miskin dengan dari pada itu secara tidak langsung Allah memberikan rezeki melalui syariat nya yaitu fidyah.

Ada beberapa uzur yang membolehkan seseorang dipersilahkan untuk berbuka dan membayar fidyah, yaitu lansia dan ibu hamil, dimana para mayoritas mufassir dan imam madzhab sepakat terhadap lansia dan ibu hamil untuk membayar fidyah. Fenomena lansia dan ibu hamil memberikan perhatian terhadap syariat Allah SWT, karena sudah barang tentu lansia identik dengan lemahnya fisik dan terkena penyakit. Wanita adalah makhluk yang mulia, Allah memberikan keistimewaan pada wanita bahkan menamakan surah dalam al-Quran yaitu surah ke 4 dalam mushaf al-Quran surah (an-Nisa) yang bermakna wanita. Wanita diembankan Allah tugas agar memperbanyak keturunan Bani Adam supaya menyebarkan ke seluruh penjuru dunia agar memakmurkan bumi Allah sebagaimana manusia adalah khalifahnya. Maka dari itu Allah memberikan 
perhatian terhadap wanita terlebih Allah SWT tidak ingin membebani hambanya (wanita) dalam beribadah, seperti halnya haid, nifas yang tidak Allah paksakan untuk melakukan shalat, demikian juga dalam berpuasa. Allah memberikan keringanan kepada wanita yang sedang mengandung janin untuk tidak memaksakan berpuasa, dengan kekhawatiran bahwa wanita yang sedang hamil rentan dengan kelemahan fisik dan berpengaruh terhadap kesehatan janin.

Menjadi kepastian dan keniscayaan bahwa manusia mengalami fase umur yang panjang atau orang lanjut usia (lansia) dan begitu juga wanita diberikan tugas untuk melahirkan anak-anak manusia. maka dengan syariatnya berupa keringanan dengan membayar kepada fakir miskin berupa bahan makanan pokok, makanan siap saji, dan atau berupa uang, Allah menginginkan hambanya tetap sehat, terhadap jiwa raga dan rohaninya. Melihat secara komprehensif, Allah SWT menginginkan orang tua renta agar tidak terbebani dalam syariatnya yaitu puasa dengan hanya membayar fidyah. Allah SWT juga menginginkan hambanya bahagia dalam masa tuanya. Dengan alternatif pembayaran fidyah, maka memiliki kesinambungan dan korelasi terhadap program pemerintah terhadap kesehatan lansia agar tetap produktif jasmani dan rohani. Demikian juga hal serupa dengan ibu hamil, bahwa syariat keringanan puasa dengan membayar fidyah kepada fakir miskin memberikan angin segar dan kemudahan terhadap ibu hamil dalam menjalankan ibadahnya kepada Allah SWT. Keringanan syariat Allah juga membantu program pemerintah terhadap kesehatan ibu hamil di Indonesia, pemahaman, dan keringanan syariat, memberikan implikasi pencegahan kematian ibu hamil.

Selain itu dengan syariat kemudahan membayar fidyah, lansia dan ibu hamil memberikan indikasi bahwa fidyah bisa menjadi salah satu sasaran dan instrument pengembangan ekonomi, sebagaimana telah dijabarkan pada analisis sebelumnya dengan menggunakan angka dari data Kementrian Kesehatan RI 2018. Tentunya semua itu harus dipahami dengan baik agar tidak menjadi pemahaman yang keliru, dan bias terhadap umat Islam mengenai penerapan pembayaran fidyah sebagai instrument pengembangan ekonomi. Pelaksanaan itu 
semua harus dipahami dengan wawasan al-Quran dan nash yang mendalam serta komprehensif.

Nilai-nilai Fidyah dalam Pengembangan Ekonomi Mustahiq

Fidyah merupakan rukhsah atau keringanan terhadap seseorang yang sulit dan tidak mampu untuk melaksanakan ibadah puasa, dan tebusan harta yang berupa bahan makan pokok atau makanan siap saji dan uang yang diberikan kepada fakir miskin melahirkan implikasi nilai atau hikmah dalam penerapannya. Adapun hikmah dan nilai-nilai dari pelaksanaan fidyah diantaranya:

1. Mendapatkan ampunan dan ridha Allah SWT.

2. Mengganti kewajiban puasa yang disebabkan uzur syari'i.

3. Membantu kebutuhan pokok fakir miskin dan ekonomi umat.

Sebagaimana tawaran dan gagasan yang telah penulis munculkan bahwa syariat fidyah bisa dijadikan instrument pengembangan ekonomi umat dengan melalui pendekatan pemeliharaan dan pendekatan berbasis sistem, pengelolaan pemberdayaan fidyah yang baik, sejalan dengan padangan maqasid aliqtishadiyah untuk menyejahterakan umat Islam pada umumnya. Pemberian bahan makanan pokok atau berupa uang kepada fakir dan miskin merupakan konteks iqtishadiyah atau bentuk bantuan kesejahteraan yaitu pengkatan ekonomi kepada sesama manusia. Penerapan fidyah jika di pandang dapat merealisasikan kesejahteraan umat Islam yang mengalami kefakiran harta dan miskin melalui pengelolaan alokasi dan distribusi yang baik yang seirama dengan maqasid aliqtishadiyah. Pengamatan fidyah pada konteks iqtishadiyah atau pengembangan ekonomi sangat dimungkinkan, jika dilihat penduduk umat Islam Indonesia dan jumlah lansia serta ibu hamil. Sewajarnya yang harus diketahui fidyah merupakan bentuk keringanan ibadah puasa bagi seorang yang beragama Islam yang tidak mampu berpuasa sehingga harus mengeluarkan dari harta berupa pembayaran dan pemberian bahan makanan pokok kepada fakir miskin.

\section{KESIMPULAN}

Konsep fidyah dalam Islam yaitu merupakan keringanan terhadap seorang muslim yang tidak mampu melaksnakan ibadah puasa berupa tebusan karena 
terdampak oleh uzur syarak atau nash, seperti manula, ibu hamil dan menyusui, orang sakit sakit parah, orang bekerja yang harus menafkahi keluarganya. Fidyah ditunaikan sebelum bulan Ramadhan yang berikutnya. Selain itu apabila dilihat dan diamati penduduk umat Islam di Indonesia, syariat fidyah memberikan pandangan bahwa fidyah bisa menjadi instrumen pengembangan ekonomi umat terkhusus fakir miskin jika dilihat dari angka lansia dan ibu hamil tentunya dengan pemahaman pelaksanaan fidyah yang berlandaskan syariat. Tujuan fidyah dalam perspektif maqashid syariah al-iqtishadiyah adalah memberikan kemudahan dalam beribadah, memberikan kebaikan dan maslahat kepada hambanya dalam ussur pemeliharaan agama, jiwa, dan harta dalam pelaksanaan fidyah. Melalui fidyah, Allah memberikan perhatian bantuan kelangsungan hidup, kesejahteraan berupa rezeki dari pembayaran fidyah dari seorang muslim yang tidak mampu berpuasa karena uzur, melalui syariatnya terhadap fakir miskin. Pemberian bahan makanan pokok atau berupa uang kepada fakir miskin merupakan konteks iqtishadiyah atau bentuk bantuan kesejahteraan kepada sesama manusia. Penerapan fidyah jika dipandang dapat merealisasikan kesejahteraan manusia melalui suatu pengelolaan alokasi dan distribusi yang baik yang seirama dengan maqasid al-iqtihsadiyah. Allah SWT memberikan terhadap lansia dan ibu hamil kemudahan agar tetap bisa menjalankan ibadah puasa dengan pengganti atau tebusan berupa pembayaran fidyah, karena sudah barang tentu suatu keniscayaan bahwa lansia sudah pasti terjadi terhadap proses kehidupan serta identik dengan kepayahan fisik dan begitu juga juga ibu hamil dan menyusui, selain memerhatikan dirinya ia juga harus memerhatikan kesehatan janin atau bayinya. Pelaksanaan syariat dari Allah SWT berupa pembayaran fidyah tentunya memiliki nilai-nilai dan hikmah, nilai-nilai tersebut mengantarkan pelakunya untuk mendapatkan keridhaan Allah SWT, fidyah dapat menggugurkan kewajiban puasa yang ditinggalkan ketika seseorang memiliki uzur syarak seperti sakit, dan tua renta sehingga membolehkannya untuk tidak berpuasa, membayar fidyah berpeluang untuk mendapatkan pahala di sisi Allah SWT, fidyah dapat membantu fakir dan miskin dalam memenuhi kebutuhan 
hidupnya dan Terjalinnya silaturrahmi antara yang membayar fidyah dengan yang menerima fidyah (fakir dan miskin). 


\section{DAFTAR PUSTAKA}

Agama RI, Al-Quran dan Terjemahnya, Klaten Jawa Tengah: Sahabat, 2013.

Akbar, Wahyu, dan Jefry Tarantang, Manajemen Zakat (Hakikat dan Spirit Alquran AtTaubah [9] : 103), Yogyakarta: K-Media, 2018.

Al-Isfahani, Mu'jam Al-Mufahras Li Alfaz Al-Qur'an, Beirut: Dar AlKutub Al'Ilmiyyah, 2004.

al-Marbawi, Muhammad Idris Abdul Rauf, Kamus Idris al-Marbawi (Indonesia: Darul Ahya' al-Kutubu al-Arabiyyah, t.th), Juz. 1.

al-Zuhayly, Wahbah, Puasa dan Itikaf-Kajian Berbagai Mazhab (terj), Penerjemah Agus Efendi dan Bahruddin Fannany, Bandung: Remaja Rosdakarya, 2005, Cet. Ke-5.

Anwar, Dessy, Kamus Bahasa Indonesia, Surabaya: Karya Abditama, 2001, Cet. Ke1.

Ar Razi, Muhammad, Mukhtar Ash Shihah, Libanon: Maktabah Lubnan, 1989, Cet. Ke1.

Arikunto, Suharsimi, Prosedur Penelitian: Suatu Pendekatan Praktek,ed. Rev., Jakarta: Rineka Cipta, 2002. al-Kubro,

Departemen Agama, Al-Qur'an dan Terjemahnya, Surabaya: Karya Agung Surabaya, 2006.

Fauzan, Salaih Bin Fauzan bin Abdullah Ali, Ringkasan Fikih Syaikh Fauzan (ter), Penerjemah Kamaluddin Sahar, Jakarta: Pustaka Azzam, 2006, Cet. Ke-1.

Hasan, A., Al-Furqan Tafsir Qur'an, jakarta: Universitas Al Azhar, Indonesia, 2010.

Helim, Abdul, Maqasid Al-syariah Versus Usul Al-Fiqh (Konsep dan Posisinya dalam Metodologi Hukum Islam), Yogyakarta: Pustaka Pelajar, 2019.

http:/humas.pasekab.go.id/berita/kadar-zakat-fitrah-di-paser-dibagi-3-kategorifidyah-rp-45-000- (online 11 Juli 2020)

https://ibtimes.id/data-populasi-penduduk-muslim-2020-indonesia-terbesar-didunia.di (online 17 juli 2020).

https://news.detik.com/berita/d-4039526/mau-bayar-fidyah-untuk-ganti-puasabegini-caranya (online 17 mei 2019). 
Idri, Hadis Ekonomi, Ekonomi Dalam Perspektif Nabi, Jakarta: Prenadamedia Group, 2015.

Irawan, Prayetno, Logika dan Prosedur Penelitian, Jakarta: STIA-LAN Press, 1999.

Irham, Pelaksanaan Fidiyah Puasa Oleh Ahli waris Untuk Keluarga Yang Meninggal Dunia Ditinjau Menurut Hukum Islam, (Studi Di Kepenghuluan Bagan Punak Pesisir Kecamatan Bangko Kabupaten Rokan Hilir), Skripsi, Riau: Universitas Islam Negeri Sultan Syarif Kasim Riau, 2011.

Kemdikbud RI, Kamus Besar Bahasa Indonesia, Jakarta: Badan Pengembangan dan Pembinaan Bahasa, 2016.

Profil Kesehatan Indoensia 2018, Kementrian Kesehatan RI 2019.

Sabiq, Sayyid, Fiqih Sunnah, jln. Matraman: Tinta Abadi Gemilang, 2013.

Sholehuddin, Wawan Shofwan, Sahum Telaah Kritis atas Sunah-Sunah dan Bid'ahBid'ahnya, Bandung: Tafakur (kelompok Humaniora), 2004.

Siddiqi, Mohammad Nejatullah, "History of Islamic Economic Thought" dalam M. Umer Capra, Lanscape Baru Perekonomian Masa Depan, terjemah oleh Amdiar Amin Dkk, Jakarta: SEBI, 2001.

Sismono, Puasa Pada Umat-Umat Dulu dan Sekarang, Jakarta: Penerbit Republika, 2010.

Sunan Al-Nasa'I, Muhaqqiq: 'Abdul al-Ghaffar Sulayman al-Bandari, Juz 2 (Bairut: Dar al- Kitab al-Ilmiyyah, 1991 M/1411 H).

Tarantang, Jefry, Teori dan Aplikasi Pemikiran Kontemporer dalam Pembaharuan Hukum Keluarga Islam, Jurnal Transformatif Vol. 2, No. 1, April 2018.

Umar ibn salih Umar, Maqasid al-syari'ah inda al-Imam al-Izza al-Din Ibn Abd alSalam, Yordania: Dar al-Nafa'is, 2003.

Yunus, Mahmud, Kamus Arab-Indonesia, (Jakarta: Hidakarya Agung, 1990). 